\title{
Tissue factor expression is associated with recurrence in patients with non-metastatic colorectal cancer
}

\author{
Hee Jae Jung ${ }^{1}$, Hye Jin Kim ${ }^{1,2}$, Kensuke Kaneko², Yoshihiro Kazama², Kazushige Kawai ${ }^{2}$, Soichiro Ishihara², Gyu-Seog Choi ${ }^{1}$ \\ ${ }^{1}$ Colorectal Cancer Center, Kyungpook National University Chilgok Hospital, School of Medicine, Kyungpook National University, Daegu, Korea; \\ ${ }^{2}$ Department of Surgical Oncology, University of Tokyo Faculty of Medicine, Tokyo, Japan
}

Purpose: Previous studies have addressed the role of the hypercoagulable state in the pathogenesis of cancer progression and metastasis. In this study, we investigated the association between coagulation factors, including tissue factor (TF) expression, platelet count, and fibrinogen level, and disease recurrence in patients with non-metastatic colorectal cancer.

Methods: Patients who underwent curative resection for stage II or III colorectal cancer between 2000 and 2007 were included in this study. Data from a prospectively maintained database were retrospectively reviewed. TF expression was determined by immunohistochemistry using an anti-TF monoclonal antibody. The Kaplan-Meier method was used to estimate 5-year disease-free survival.

Results: TF was highly expressed in 257 of 297 patients (86.5\%). TF expression was not significantly associated with the platelet counts $(P=0.180)$ or fibrinogen level $(P=0.281)$. The 5 -year disease-free survival rate was lower in patients with high TF expression than in patients with low TF expression (72.3\% vs. 83.9\%, $\mathrm{P}=0.074)$. In Cox hazard analysis, high TF expression was an independent risk factor for tumor recurrence (hazard ratio [HR] 2.446; 95\% confidence interval [Cl], 1.054-5.674; $\mathrm{P}=0.037)$. Undifferentiated histologic type ( $\mathrm{HR}, 2.911 ; 95 \% \mathrm{Cl}$, 1.308-6.481; $\mathrm{P}=0.009)$, venous invasion ( $\mathrm{HR}, 2.784 ; 95 \% \mathrm{Cl}, 1.431-5.417 ; \mathrm{P}=0.003)$, and lymph node metastasis $(\mathrm{HR}, 2.497 ; 95 \% \mathrm{Cl}$, $1.499-4.158 ; P<0.001)$, were also significantly associated with disease recurrence.

Conclusion: TF expression is associated with a recurrence in patients with non-metastatic colorectal cancer. However, further studies are required to clarify the underlying mechanisms relating TF expression with oncologic outcomes and its potential role as a therapeutic target.

Keywords: Colonic neoplasms, Prognosis, Survival, Immunohistochemistry

\section{INTRODUCTION}

Malignancy is a known pro-coagulant state, predisposing to thrombosis. A number of coagulation abnormalities have been reported to be associated with tumor growth, metastasis, and recurrence in different types of solid tumor including esophageal, gastric, pancreatic, ovarian, lung, and colorectal cancer [1-4].

Tissue factor (TF) is a transmembrane glycoprotein that has a cen-

Received: Oct 10, 2018 Revised: Dec 19, 2018 Accepted: Dec 20, 2018

Correspondence to: Gyu-Seog Choi

Colorectal Cancer Center, Kyungpook National University Chilgok

Hospital, 807 Hoguk-ro, Buk-gu, Daegu 41404, Korea

Tel: +82-53-200-2166, Fax: +82-53-200-2027

E-mail: kyuschoi@mail.knu.ac.kr

ORCID: Hye Jin Kim (https://orcid.org/0000-0002-3370-5985), Gyu-Seog Choi (https://orcid.org/0000-0001-5476-4610)

Copyright (C) 2018 Korean Society of Surgical Oncology

This is an Open Access article distributed under the terms of the Creative Commons Attribution Non-Commercial License (http://creativecommons.org/licenses/by-nc/4.0) which permits unrestricted non-commercial use, distribution, and reproduction in any medium, provided the original work is properly cited. tral role in initiating the coagulation cascade [5,6]. TF expression has been identified immunohistochemically in epithelial tissues, specifically the skin, the mucosal surfaces of the gut, and genitourinary system [7]. However, it has also been found to be overexpressed in cancer cells. A direct association between elevated TF expression and advanced stages of malignancy has been confirmed in several different types of cancers [8-11]. More recent studies have suggested that TF expression contributed to metastasis by interfering with cell signaling pathways and presenting the proteolytic activity by the TF/ factor VI activated complex. Therefore, increased TF expression is associated with a worse oncologic outcome [12-14].

Fibrinogen, the most abundant plasma coagulation factor, is a key protein in coagulation pathway, clot formation, and wound healing, and is required for platelet aggregation, which is the final step in the coagulation cascade. It has previously been suggested that fibrinogen and platelets have a role in carcinogenesis, and their levels are associated with tumor progression, metastasis, and angiogenesis [15-17]. Furthermore, recent studies have shown that elevated fibrinogen plasma levels and platelet counts are a useful 
prognostic parameter for recurrence and overall survival $[18,19]$.

Although previous studies suggested a close relationship between colorectal cancer and hypercoagulability, TF was not fully investigated in colorectal cancer. In this study, therefore, we examined the TF expression in patients with non-metastatic colorectal cancer who underwent curative resection. We then analyzed the relationship between TF expression and other coagulation abnormalities, including thrombocytosis and hyperfibrinogenemia, as well as the prognostic factors of tumor recurrence to determine the prognostic role of TF expression.

\section{METHODS}

Data pertaining to a total of 305 patients with stage II or III colorectal cancer who underwent curative resection between 2000 and 2007 at The University of Tokyo Hospital were collected retrospectively from a prospectively maintained database. Patients who had a synchronous extracolonic tumor, apparent acute inflammatory disease, severe liver disease, distant metastasis, or preoperative chemotherapy or radiotherapy were excluded. The study was approved by the Institutional Review Board of The University of Tokyo Hospital and performed in accordance with the principles of the Declaration of Helsinki. The informed consent was waived.

After curative surgery, patients were followed up postoperatively every 3 months for the first 2 years, every 6 months for the next 3 years, and once annually thereafter. Patients were clinically examined and tumor makers were measured at each visit. Full colonoscopy was performed 1 year after surgery, and then once every 3 years. Computed tomography scans were obtained on the basis of individual follow-up regimens (generally every 6-12 months). Recurrences were confirmed radiologically or by biopsy. Locoregional recurrence was defined as tumor regrowth within the pelvis, perineum, or anastomosis site; whereas, distant metastasis was defined as any other recurrence outside of the pelvis.

\section{TF immunohistochemistry}

Immunohistochemical staining was performed using formalin-fixed, paraffin-embedded, $3 \mu \mathrm{m}$-thick colorectal cancer tissue sections. These tissues were deparaffinized in xylene and rehydrated in graded alcohols. For antigen retrieval, sections were boiled in 10 $\mathrm{mM}$ sodium citrate buffer ( $\mathrm{pH}$ 6.0) for 20 minutes in a microwave oven. Endogenous peroxidase activity was quenched using methanol and 3\% hydrogen peroxide solution for 15 minutes. After washing with phosphate-buffered saline (PBS), the sections were incubated overnight at $4^{\circ} \mathrm{C}$ with a rabbit polyclonal anti-TF antibody (FL-295, dilution 1:75; Santa Cruz Biotechnology, Dallas, TX, USA). After washing in PBS, the sections were incubated with a secondary anti-rabbit biotinylated antibody (Santa Cruz Biotechnology) for 20 minutes at room temperature. After washing again in PBS, these slides were treated with peroxidase-conjugated streptavidin for 10 minutes and developed by immersion in a $0.01 \%$ hydrogen peroxide solution and diaminobenzidine tetrahydrochloride. Light counterstaining was performed with Mayer's hematoxylin.

Immunoreactivity was assessed by Y.K and K.K who had no knowledge of the associated clinical background. Immunoreactivity of TF was classified as "high" when the cytoplasmic or membrane staining was at least of moderate intensity and occupied more than $75 \%$ of the cancer cells in each section.

\section{Statistical analysis}

Statistical calculations were performed using statistical software, SPSS version 17.0 (SPSS, Inc., Chicago, IL, USA). Continuous data were analyzed by comparing the mean value of each variable between groups by using the Student t-test. Categorical variables were compared using Fisher exact test or the chi-square test, as appropriate. The probability of disease-free survival was estimated using the Kaplan-Meier method. The log-rank test was employed to compare survival between groups. A P-value of $<0.05$ was considered statistically significant.
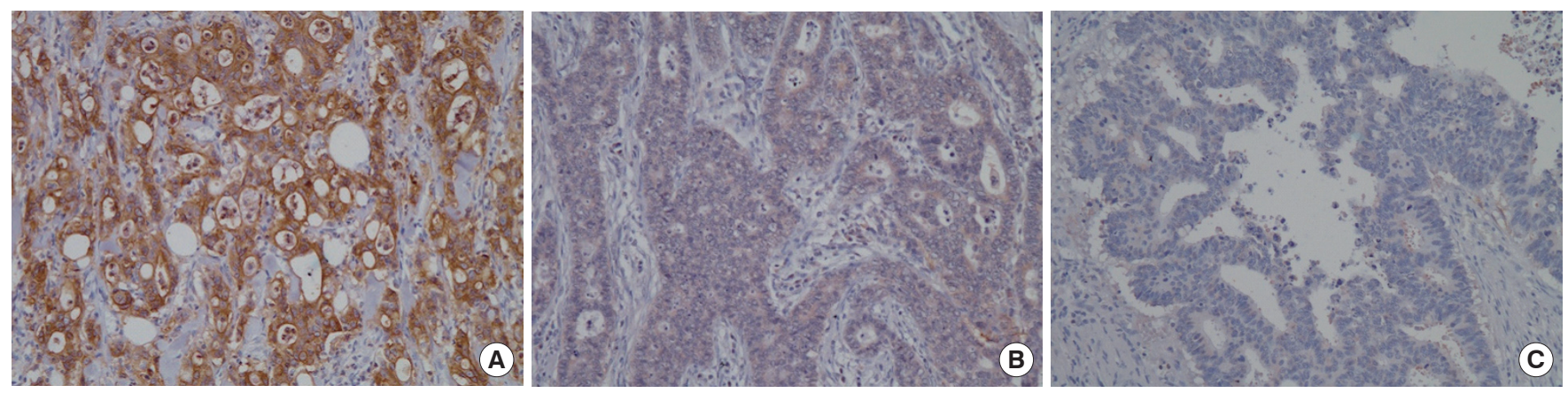

Fig. 1. Immunohistochemical staining with an anti-tissue factor antibody. (A) Strong immunoreactivity (B) moderate immunoreactivity, and (C) no immunoreactivity. Magnification, x200. 


\section{RESULTS}

A total of 297 patients were eligible for inclusion in this study. TF expression was high in 257 of the 297 patients (86.5\%) (Fig. 1). Table 1 summarizes the associations between TF expression and the clinicopathologic characteristics of the patients. TF expression did not differ significantly according to age, sex, histologic differentiation, depth of invasion, or lymph node metastasis. Further, high TF expression was not significantly associated with the platelet count $(\mathrm{P}=0.180)$ or fibrinogen level $(\mathrm{P}=0.281)$.

The associations between other coagulation abnormalities, thrombocytosis (platelet count $\geq 370 \times 10^{3} / \mu \mathrm{L}$ ) and hyperfibrinogenemia (fibrinogen level $\geq 350 \mathrm{mg} / \mathrm{dL}$ ), and the clinicopathologic characteristics of patients are summarized in Table 2 . In both comparisons, advanced tumor depth was significantly associated with thrombocytosis $(\mathrm{P}=0.024)$ and hyperfibrinogenemia $(\mathrm{P}=0.001)$.

The median clinical follow-up was 69 months (interquartile range, 26-112 months). A total of 73 patients experienced tumor recurrences during the follow-up period, but this occurred more frequently in the high TF expression group than in the low TF expression group (67 patients [26.1\%] vs. 6 patients [15.0\%], $\mathrm{P}=$ 0.167). Fig. 2 shows the Kaplan-Meier survival curves of patients according to TF expression. The 5-year disease-free survival rate in patients with high TF expression was $72.3 \%$, compared to $83.9 \%$ for those with low TF expression although this difference was not
Table 1. Correlations between tissue factor expression and clinicopathologic characteristics

\begin{tabular}{|c|c|c|c|}
\hline Characteristic & $\begin{array}{l}\text { Low TF expression } \\
\qquad(n=40)\end{array}$ & $\begin{array}{l}\text { High TF expression } \\
\qquad(n=257)\end{array}$ & P-value \\
\hline Age (yr) & $67.6 \pm 9.9$ & $67.7 \pm 11.5$ & 0.923 \\
\hline Sex & & & 0.084 \\
\hline Male & $19(47.5)$ & $160(62.3)$ & \\
\hline Female & $21(52.5)$ & $97(37.7)$ & \\
\hline Tumor location & & & 0.343 \\
\hline Colon & $26(65.0)$ & $188(73.2)$ & \\
\hline Rectum & $14(35.0)$ & $69(26.8)$ & \\
\hline Histologic differentiation & & & 0.280 \\
\hline Well or moderately & 4 (10.0) & $14(5.4)$ & \\
\hline Others & $36(90.0)$ & $243(94.6)$ & \\
\hline Lymphatic invasion & & & 0.853 \\
\hline Negative & $29(72.5)$ & $178(69.3)$ & \\
\hline Positive & $11(27.5)$ & 79 (30.7) & \\
\hline Venous invasion & & & 0.718 \\
\hline Negative & $14(35.0)$ & $82(31.9)$ & \\
\hline Positive & $26(65.0)$ & $175(68.1)$ & \\
\hline Depth of tumor invasion & & & 0.153 \\
\hline $\mathrm{T} 1 \& \mathrm{~T} 2$ & $5(12.5)$ & $14(5.4)$ & \\
\hline T3\&T4 & 35 (87.5) & $243(94.6)$ & \\
\hline Lymph node metastasis & & & 0.172 \\
\hline Negative & $17(42.5)$ & $142(55.3)$ & \\
\hline Positive & $23(57.5)$ & $115(44.7)$ & \\
\hline Platelet count $\left(\times 10^{3} / \mu \mathrm{L}\right)$ & $289.7 \pm 106.0$ & $269.2 \pm 86.0$ & 0.180 \\
\hline Fibrinogen (mg/dL) & $363.3 \pm 76.0$ & $379.2 \pm 85.3$ & 0.281 \\
\hline Disease recurrence & $6(15.0)$ & $67(26.1)$ & 0.167 \\
\hline
\end{tabular}

Values are presented as mean \pm standard deviation or number (\%). TF, tissue factor.

Table 2. Correlation between platelet count or fibrinogen level and clinicopathologic characteristics

\begin{tabular}{|c|c|c|c|c|c|c|}
\hline \multirow{2}{*}{ Characteristic } & \multicolumn{2}{|c|}{ Platelet count $\left(\times 10^{3} / \mu \mathrm{L}\right)$} & \multirow{2}{*}{ P-value } & \multicolumn{2}{|c|}{ Fibrinogen (mg/dL) } & \multirow{2}{*}{ P-value } \\
\hline & $\geq 370(n=36)$ & $<370(n=260)$ & & $\geq 350(n=168)$ & $<350(n=111)$ & \\
\hline Age (yr) & $64.8 \pm 10.6$ & $68.1 \pm 11.3$ & 0.108 & - & - & - \\
\hline Sex & & & 0.047 & & & 0.619 \\
\hline Male & $16(44.4)$ & $162(62.3)$ & & $97(57.7)$ & $68(61.3)$ & \\
\hline Female & $20(55.6)$ & $98(37.7)$ & & 71 (42.3) & 43 (38.7) & \\
\hline Tumor location & & & 0.697 & & & 0.784 \\
\hline Colon & $25(69.4)$ & $188(72.3)$ & & $121(72.0)$ & $82(73.9)$ & \\
\hline Rectum & $11(30.6)$ & $72(27.7)$ & & $47(28.0)$ & $29(26.1)$ & \\
\hline Histologic differentiation & & & 0.252 & & & 0.788 \\
\hline Well or moderately & 32 (88.9) & $246(94.6)$ & & $10(6.0)$ & $5(4.5)$ & \\
\hline Others & $4(11.1)$ & $14(5.4)$ & & $158(94.0)$ & 106 (95.5) & \\
\hline Lymphatic invasion & & & 0.847 & & & 0.596 \\
\hline Negative & $26(72.2)$ & $180(69.2)$ & & $119(70.8)$ & 75 (67.6) & \\
\hline Positive & $10(27.8)$ & 80 (30.8) & & 49 (29.2) & $36(32.4)$ & \\
\hline Venous invasion & & & 0.852 & & & 0.603 \\
\hline Negative & $11(30.6)$ & 85 (32.7) & & 57 (33.9) & $34(30.6)$ & \\
\hline Positive & $25(69.4)$ & $175(67.3)$ & & 111 (66.1) & $77(69.4)$ & \\
\hline Depth of tumor invasion & & & 0.024 & & & 0.001 \\
\hline $\mathrm{T} 1 \& \mathrm{~T} 2$ & 0 & $19(7.3)$ & & $4(2.4)$ & 14 (12.6) & \\
\hline T3\&T4 & $36(100)$ & $241(92.7)$ & & $164(97.6)$ & $97(87.4)$ & \\
\hline Lymph node metastasis & & & 0.109 & & & 0.327 \\
\hline Negative & 24 (66.7) & 134 (51.5) & & 94 (56.0) & 55 (49.5) & \\
\hline Positive & $12(33.3)$ & $126(48.5)$ & & 74 (44.0) & $56(50.5)$ & \\
\hline
\end{tabular}

Values are presented as mean \pm standard deviation or number $(\%)$. 

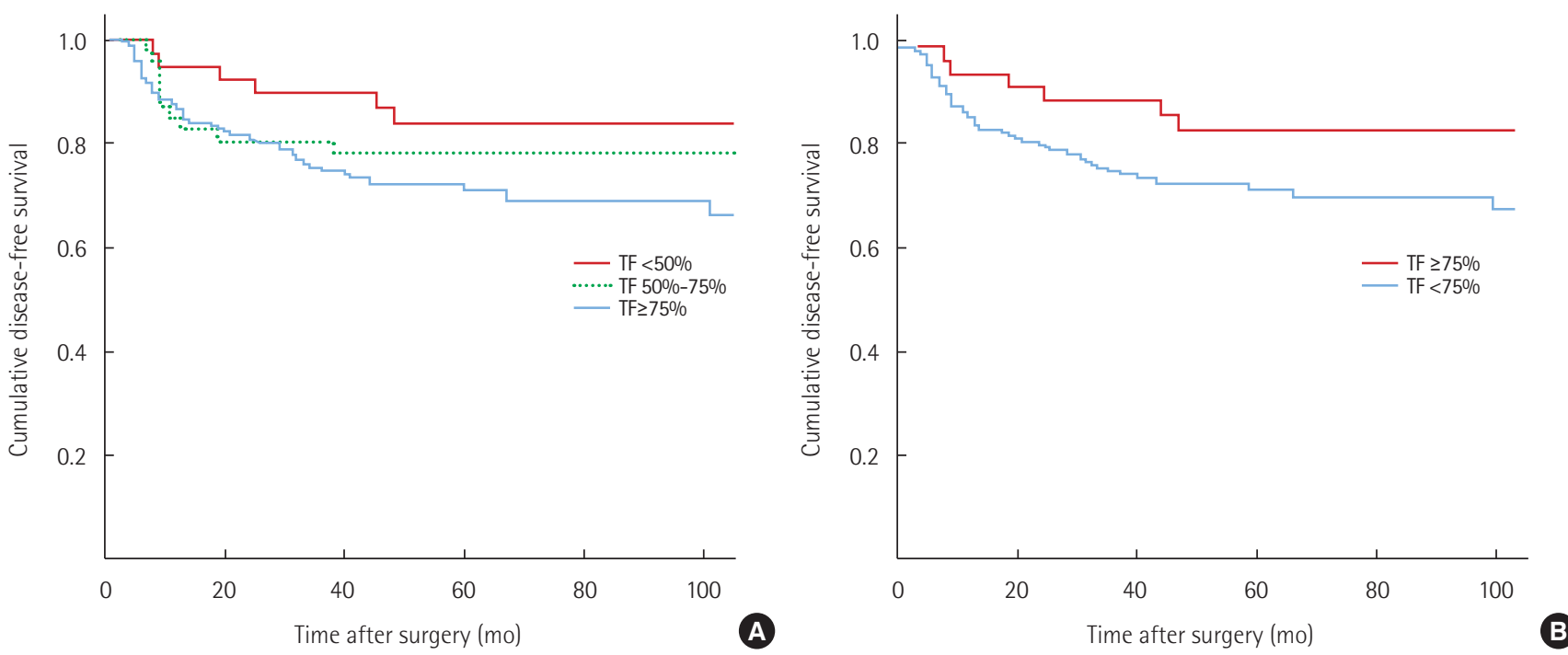

Fig. 2. Kaplan-Meier curves for disease-free survival according to the extent of tissue factor expression. (A) Tissue factor (TF) $\geq 75 \%$ vs. $50 \%-75 \%$ vs. $<50 \%$ and (B) TF $\geq 75 \%$ vs. $<75 \%(P=0.074)$.

Table 3. Univariate analysis for disease-free survival

\begin{tabular}{|c|c|c|c|}
\hline Characteristic & No. & 5-Year DFS (\%) & P-value \\
\hline Age (yr) & & & 0.687 \\
\hline$<60$ & 64 & 73.5 & \\
\hline$\geq 60$ & 233 & 74.0 & \\
\hline Sex & & & 0.826 \\
\hline Male & 179 & 74.0 & \\
\hline Female & 118 & 73.6 & \\
\hline Histologic differentiation & & & 0.092 \\
\hline Well or moderately & 278 & 75.1 & \\
\hline Others & 19 & 53.8 & \\
\hline Lymphatic invasion & & & 0.012 \\
\hline Negative & 207 & 82.7 & \\
\hline Positive & 90 & 65.3 & \\
\hline Venous invasion & & & $<0.001$ \\
\hline Negative & 96 & 87.7 & \\
\hline Positive & 201 & 67.1 & \\
\hline Depth of tumor invasion & & & 0.475 \\
\hline $\mathrm{T} 1 \& \mathrm{~T} 2$ & 19 & 65.2 & \\
\hline Т3\&Т4 & 278 & 74.5 & \\
\hline Lymph node metastasis & & & $<0.001$ \\
\hline Negative & 159 & 83.8 & \\
\hline Positive & 138 & 63.4 & \\
\hline Platelet count $\left(\times 10^{3} / \mu \mathrm{L}\right)$ & & & 0.479 \\
\hline$\geq 370$ & 36 & 79.3 & \\
\hline$<370$ & 260 & 73.0 & \\
\hline Fibrinogen (mg/dL) & & & 0.234 \\
\hline$\geq 350$ & 168 & 73.3 & \\
\hline$<350$ & 111 & 77.7 & \\
\hline Tissue factor expression & & & 0.074 \\
\hline Negative & 40 & 83.9 & \\
\hline Positive & 257 & 72.3 & \\
\hline
\end{tabular}

DFS, disease-free survival.
Table 4. Cox proportional hazards model for disease-free survival

\begin{tabular}{lcr}
\hline Variable & HR (95\% Cl) & P-value \\
\hline $\begin{array}{l}\text { Histologic differentiation } \\
\text { (differentiation vs. others) }\end{array}$ & $2.911(1.308-6.481)$ & 0.009 \\
Lymphatic invasion (positive vs. negative) & $1.227(0.759-1.983)$ & 0.405 \\
Venous invasion (positive vs. negative) & $2.784(1.431-5.417)$ & 0.003 \\
Lymph node metastasis (positive vs. negative) & $2.497(1.499-4.158)$ & $<0.001$ \\
\hline Tissue factor expression (positive vs. negative) & $2.446(1.054-5.674)$ & 0.037 \\
\hline
\end{tabular}

$H R$, hazard ratio; $\mathrm{Cl}$, confidence interval.

statistically significant $(\mathrm{P}=0.074)$. When we sub-classified the proportion of TF positive cells in the section as $<50 \%, 50 \%-75 \%$, and $\geq 75 \%$, TF expression $<50 \%$ was associated with a better 5 -year disease-free survival rate than TF expression 50\%-75\% (83.6\% vs. $78.2 \%, \mathrm{P}=0.428$ ) or $\mathrm{TF}$ expression $\geq 75 \%$ ( $83.6 \%$ vs. $70.8 \%$, $\mathrm{P}=0.060$ ), although this difference was also not statistically significant (Fig. 2).

In a univariate analysis, lymphatic invasion $(\mathrm{P}=0.012)$, venous invasion $(\mathrm{P}<0.001)$, and lymph node metastasis $(\mathrm{P}<0.001)$ were significantly associated with disease recurrence. Histologic differentiation and TF expression showed the trend, but these were not statistically significant $(\mathrm{P}=0.092$ and $\mathrm{P}=0.074$, respectively). However, thrombocytosis and hyperfibrinogenemia were not significantly associated with recurrence $(\mathrm{P}=0.479$ and $\mathrm{P}=0.234$, respectively) (Table 3). Variables in the univariate analysis with a P-value $<0.2$ were included in the multivariate analysis. In the multivariate Cox hazard model, undifferentiated histologic type (hazard ratio [HR], 2.911; 95\% confidence interval [CI], 1.3086.481; $\mathrm{P}=0.009)$, venous invasion ( $\mathrm{HR}, 2.784$; 95\% CI, 1.431 - 
5.417; $\mathrm{P}=0.003$ ), lymph node metastasis (HR, 2.497; 95\% CI, 1.499-4.158; $\mathrm{P}<0.001$ ), and high TF expression (HR, 2.446; 95\% $\mathrm{CI}, 1.054-5.674 ; \mathrm{P}=0.037)$ were all found to be significantly associated with disease-free survival (Table 4 ).

\section{DISCUSSION}

To assess the risk of relapse among non-metastatic colorectal cancer patients who have undergone curative resection would be of great clinical implications. In this study, we evaluated the prognostic role of coagulation factors, including TF expression, the fibrinogen level, and the platelet count in patients with stage II or III colorectal cancer. We found a significant association between high TF expressions in tumor cells and a high tumor recurrence rate in multivariate analysis. However, TF expression was not correlated with other coagulation abnormalities, including an elevated fibrinogen level and platelet counts, and these were not significantly associated with tumor recurrence.

TF is a $47-\mathrm{kDa}$ transmembrane glycoprotein that is essential for hemostasis. It binds to the coagulation serine protease factor VII/ VIIa (FVII/VIIa) to form a protein complex that functions as the primary initiator of coagulation. The TF/FVIIa complex activates both factor X and factor IX and leads to thrombin generation and fibrin formation, both of which are required for physiologic hemostasis. Thrombin also activates platelets through the cleavage of protease-activated receptors $[5,6]$. In addition to its role in hemostasis, TF has a possible role in cancer growth, metastasis, and recurrence. TF is constitutively expressed in various extravascular cells, but it is also aberrantly expressed in cancer cells and endothelial cells within tumors. It induces angiogenesis by up-regulating vascular endothelial growth factor and down-regulating the angiogenesis inhibitor thrombospondin, in a mechanism that is independent of coagulation [20]. Thus, TF may also contribute to cancer coagulopathy, intratumoral angiogenesis, and tumor progression [8-11]. This is further supported by the findings that a selective reduction in TF expression in colorectal cancer cells using small interfering RNA dramatically reduced tumor growth in a mouse model of malignancy [21].

Previous studies have reported significant association between the immunohistochemical localization of the TF antigen in tumors and poor oncologic outcomes in colorectal cancer. Seto et al. [9] showed that TF expression in colorectal cancer was an independent risk factor for hepatic metastasis and poor prognosis in 67 colorectal cancer patients. Shigemori et al. [22] reported that TF expression was detected in $57 \%$ of 79 colorectal tumors and in $88 \%$ of 17 liver metastatic tumors from primary colorectal cancer. Findings from these two studies suggest that the immunoreactivity of
TF is closely related to metastasis in colorectal cancer. In agreement with these results, our study also showed that high TF expression in colorectal cancer cells was an independent prognostic factor for disease recurrence after adjustment for confounding variables, such as histologic differentiation, venous invasion, and lymph node metastasis in stage II or III colorectal cancer.

There is no standard classification of high TF expression in immunohistochemical staining. Some authors have suggested that high or positive TF expression should be determined on the basis of intensity of staining [23], whereas other authors have suggested the area of the section staining positive for TF should be the basis for determining a high or positive TF expression [15,24]. In this study, we mainly applied the latter, and considered a tumor to be high TF expression when more than $75 \%$ of the cancer cells expressed TF. We also supplement our classification for high TF expression by adding to the intensity of staining (at least moderate intensity). In this study, the proportion of patients with high TF expression $(86.5 \%)$ was higher than reported in previous studies (approximately 50\%) $[14,23,24]$. The discrepancy between our findings for high TF expression and those of previous studies might be explained by our inclusion of only stage II or III colorectal cancer patients, most of whom had T3 or T4 tumors (278 of 297 patients), because previous studies reported that high TF expression was associated with advanced clinical stage, tumor depth, and tumor size [25]. This assumption also might explain the lack of any apparent relationship between TF expression and patient's clinicopathologic characteristics in this study. Mostly advanced tumor stage (T3 or T4) in this study may have made it more difficult to draw the statistically significant associations between TF expression and those factors.

None of the previous studies addressing TF expression in colorectal cancers investigated the relationship between TF expression and thrombocytosis or hyperfibrinogenemia. However, contrary to our initial hypothesis, we failed to find associations among the coagulation factors. Also, we did not observe any significant association between thrombocytosis or hyperfibrinogenemia and disease recurrence. We consider it also related to selection bias, because thrombocytosis and hyperfibrinogenemia are also known to be related to clinical stage, tumor depth and size $[16,18,19]$. It was therefore difficult to find a statistically significant relationship between TF expression, serum fibrinogen levels and platelet counts. However, thrombocytosis or hyperfibrinogenemia is known to be a poor prognostic factor in colorectal cancer. Therefore, further large cohort study is required to evaluate this relationship.

We found that colorectal patients with high TF expression showed a poorer oncologic outcome than those with low TF expression, suggesting that TF can be a potential target in cancer therapy. Various TF-directed therapeutic agents are being devel- 
oped, including TF antagonists such as recombinant TF pathway inhibitors and anti-TF antibodies, and other agents that act indirectly on TF expression, such as vitamin D3, retinoids, and heparin [26-28]. Preclinical studies have shown that some of these agents have antitumor and antiangiogenic effects [29]. TF-targeting therapeutic agents have been tested for the treatment of both cancer and non-cancerous diseases. The results of these trials indicate that these agents can destroy tumor vessels by targeting tumor vascular endothelial cells. When administered systemically, these agents can penetrate tumor tissue and kill the tumor cells through leaks in the tumor vasculature. In a mouse model of pulmonary metastasis, inhibition of TF with a variety of agents, such as anti-TF antibodies and a TF pathway inhibitor, reduced tumor metastasis [30].

This study had several limitations, including the selection biases that are inherent in any retrospective analysis. However, we included a relatively high number of patients with stage II or III colorectal cancer, and the follow-up period was relatively long. Because we only included patients with stage II or III colorectal cancer, we did not observe any apparent relationship between TF expression and patient characteristics. However, a number of stage II or III colorectal cancer patients experienced tumor recurrence and death. There is a clinical implication in evaluating prognostic factors for disease recurrence in these patients and it would help to select patients who would benefit from aggressive adjuvant treatment or molecular targeted therapy. Nevertheless, further study is required to evaluate the implication of TF expression in all stages of colorectal cancer. The second limitation was the accuracy with which TF expression was evaluated. However, two pathologists assessed immunoreactivity without knowing the clinical background of the patients, and a Cohen's kappa test for concordance between the two pathologists gave a value of 0.746 , indicating good agreement between them. Therefore, our results suggest that immunohistochemistry is a reliable tool for assessing TF expression in tumors, which in turn could allow the prediction of the oncologic outcome in cancer patients.

In this study, we showed that high levels of TF expression in colorectal cancer cells was associated with disease recurrence in patients with stage II or III colorectal cancer. TF expression could be considered as a prognostic indicator for patients with non-metastatic colorectal cancer. Therefore, the determination of the TF expression status may provide additional prognostic information. However, further studies are needed to establish the underlying mechanism relating TF expression with oncologic outcome. Further studies are also needed to determine the true clinical usefulness of these findings and identify possible roles for TF as a clinical marker and therapeutic target.

\section{CONFLICT OF INTEREST}

No potential conflict of interest relevant to this article was reported.

\section{ACKNOWLEDGMENTS}

This work was supported under the framework of an international cooperation program managed by the National Research Foundation of Korea (2017K2A9A2A07000211, FY2018).

Author contributions: Analysis and writing of manuscript are attributed to Hee Jae Jung. Responsibility to correspondence and study proposal are attributed to Gyu-Seog Choi. Enrollment of patients and study proposal are attributed to Hye Jin Kim, Kensuke Kaneko, Yoshihiro Kazama, Kazushige Kawai, and Soichiro Ishihara.

\section{REFERENCES}

1. Naina HV, Harris S. Paraneoplastic thrombocytosis in ovarian cancer. N Engl J Med 2012;366:1840.

2. Wang L, Huang X, Chen Y, Jin X, Li Q, Yi TN. Prognostic value of TP/PD-ECGF and thrombocytosis in gastric carcinoma. Eur J Surg Oncol 2012;38:568-73.

3. Komurcuoglu B, Ulusoy S, Gayaf M, Guler A, Ozden E. Prognostic value of plasma D-dimer levels in lung carcinoma. Tumori 2011;97:743-8.

4. Sasaki K, Kawai K, Tsuno NH, Sunami E, Kitayama J. Impact of preoperative thrombocytosis on the survival of patients with primary colorectal cancer. World J Surg 2012;36:192-200.

5. Key NS, Geng JG, Bach RR. Tissue factor; from Morawitz to microparticles. Trans Am Clin Climatol Assoc 2007;118:165-73.

6. Carmeliet P. Biomedicine: clotting factors build blood vessels. Science 2001;293:1602-4.

7. Drake TA, Morrissey JH, Edgington TS. Selective cellular expression of tissue factor in human tissues. Implications for disorders of hemostasis and thrombosis. Am J Pathol 1989;134:1087-97.

8. Koomagi R, Volm M. Tissue-factor expression in human nonsmall-cell lung carcinoma measured by immunohistochemistry: correlation between tissue factor and angiogenesis. Int J Cancer 1998;79:19-22.

9. Seto S, Onodera H, Kaido T, Yoshikawa A, Ishigami S, Arii S, et al. Tissue factor expression in human colorectal carcinoma: correlation with hepatic metastasis and impact on prognosis. Cancer 2000;88:295-301.

10. Rickles FR, Patierno S, Fernandez PM. Tissue factor, thrombin, and cancer. Chest 2003;124:58S-68S.

11. Bromberg ME, Sundaram R, Homer RJ, Garen A, Konigsberg WH. Role of tissue factor in metastasis: functions of the cytoplas- 
mic and extracellular domains of the molecule. Thromb Haemost 1999;82:88-92.

12. Akashi T, Furuya Y, Ohta S, Fuse H. Tissue factor expression and prognosis in patients with metastatic prostate cancer. Urology 2003;62:1078-82.

13. Han LY, Landen CN Jr, Kamat AA, Lopez A, Bender DP, Mueller P, et al. Preoperative serum tissue factor levels are an independent prognostic factor in patients with ovarian carcinoma. J Clin Oncol 2006;24:755-61.

14. Khorana AA, Ahrendt SA, Ryan CK, Francis CW, Hruban RH, Hu YC, et al. Tissue factor expression, angiogenesis, and thrombosis in pancreatic cancer. Clin Cancer Res 2007;13:2870-5.

15. Yamashita H, Kitayama J, Taguri M, Nagawa H. Effect of preoperative hyperfibrinogenemia on recurrence of colorectal cancer without a systemic inflammatory response. World J Surg 2009;33:1298305 .

16. Tang L, Liu K, Wang J, Wang C, Zhao P, Liu J. High preoperative plasma fibrinogen levels are associated with distant metastases and impaired prognosis after curative resection in patients with colorectal cancer. J Surg Oncol 2010;102:428-32.

17. Gasic GJ, Gasic TB, Galanti N, Johnson T, Murphy S. Platelet-tumor-cell interactions in mice: the role of platelets in the spread of malignant disease. Int JCancer 1973;11:704-18.

18. Kawai K, Kitayama J, Tsuno NH, Sunami E, Nagawa H. Hyperfibrinogenemia after preoperative chemoradiotherapy predicts poor response and poor prognosis in rectal cancer. Int J Colorectal Dis 2011;26:45-51.

19. Cravioto-Villanueva A, Luna-Perez P, Gutierrez-de la Barrera M, Martinez-Gomez H, Maffuz A, Rojas-Garcia P, et al. Thrombocytosis as a predictor of distant recurrence in patients with rectal cancer. Arch Med Res 2012;43:305-11.

20. Zhang Y, Deng Y, Luther T, Muller M, Ziegler R, Waldherr R, et al. Tissue factor controls the balance of angiogenic and antiangiogenic properties of tumor cells in mice. J Clin Invest 1994;94:1320-7.

21. Yu JL, May L, Lhotak V, Shahrzad S, Shirasawa S, Weitz JI, et al.
Oncogenic events regulate tissue factor expression in colorectal cancer cells: implications for tumor progression and angiogenesis. Blood 2005; 105:1734-41.

22. Shigemori C, Wada H, Matsumoto K, Shiku H, Nakamura S, Suzuki H. Tissue factor expression and metastatic potential of colorectal cancer. Thromb Haemost 1998;80:894-8.

23. Chen L, Luo G, Tan Y, Wei J, Wu C, Zheng L, et al. Immunolocalisation of tissue factor in esophageal cancer is correlated with intratumoral angiogenesis and prognosis of the patient. Acta Histochem 2010;112:233-9.

24. Nitori N, Ino Y, Nakanishi Y, Yamada T, Honda K, Yanagihara K, et al. Prognostic significance of tissue factor in pancreatic ductal adenocarcinoma. Clin Cancer Res 2005;11:2531-9.

25. Rao B, Gao Y, Huang J, Gao X, Fu X, Huang M, et al. Mutations of p53 and K-ras correlate TF expression in human colorectal carcinomas: TF downregulation as a marker of poor prognosis. Int J Colorectal Dis 2011;26:593-601.

26. Laterre PF, Wittebole X, Collienne C. Pharmacological inhibition of tissue factor. Semin Thromb Hemost 2006;32:71-6.

27. Tenno T, Oberg F, Mackman N, Nilsson K, Siegbahn A. PML/ RARalpha plays a role for basal activity and retinoid-induced repression of the tissue factor promoter in acute promyelocytic leukemia cells. Thromb Haemost 2003;90:930-9.

28. Ma Q, Tobu M, Schultz C, Jeske W, Hoppensteadt D, Walenga J, et al. Molecular weight dependent tissue factor pathway inhibitor release by heparin and heparin oligosaccharides. Thromb Res 2007; 119:653-61.

29. Hembrough TA, Swartz GM, Papathanassiu A, Vlasuk GP, Rote WE, Green SJ, et al. Tissue factor/factor VIIa inhibitors block angiogenesis and tumor growth through a nonhemostatic mechanism. Cancer Res 2003;63:2997-3000.

30. Amirkhosravi A, Meyer T, Chang JY, Amaya M, Siddiqui F, Desai $\mathrm{H}$, et al. Tissue factor pathway inhibitor reduces experimental lung metastasis of B16 melanoma. Thromb Haemost 2002;87:930-6. 